\title{
A review on the influence of intelligent power consumption technologies on the utilization rate of distribution network equipment
}

\author{
Yuqing He${ }^{1}$, Yuehui Chen ${ }^{1}$, Zhiqiang Yang ${ }^{2 *}$, Hongbin $\mathrm{He}^{1}$ and Li Liu ${ }^{1}$
}

\begin{abstract}
The economy of distribution networks largely depends on the utilization rate of distribution network equipment. Most of the emerging intelligent power consumption technologies have a positive effect on equipment utilization and their use can save investment of distribution networks. In this paper, the influence of intelligent power consumption technologies on the utilization rate of distribution network equipment is reviewed. The evaluation methods and indexes are assessed first and then intelligent power consumption equipment with energy storage function, vehicle-to-grid (V2G) technology and time-of-use (TOU) tariff are reviewed respectively. It is concluded that these intelligent power consumption technologies and measures have great potential to improve utilization rate of distribution network equipment because of their effective improvement to power load. Meanwhile, recommendations on how to utilize these intelligent power consumption technologies to improve utilization rate of distribution network equipment are proposed.
\end{abstract}

Keywords: Intelligent power consumption technologies, Energy storage, Vehicle-to-grid, Time-of-use tariff

\section{Introduction}

The utilization rate of distribution network equipment, which plays an essential role in power system economy, has received extensive attentions with the rapid development of smart grid [1]. Over the past decade, the investment on the construction of China's distribution system has reached 150 billion dollars, and is still increasing. Applying intelligent power consumption technologies to improve the utilization rate of distribution network equipment can significantly reduce the required distribution network investment. Renewable and sustainable energy is widely used in power industry due to its great development potential, cleanliness and low pollution [2]. However, the application of renewable and sustainable energy in power industry is affected by geography, weather and other factors, which can cause fluctuations of distribution network and result in unnecessary losses.

\footnotetext{
* Correspondence: 594244714@qq.com

${ }^{2}$ College of Electric and Information Engineering, Hunan University, Yuelu

District, Changsha, Hunan Province, China

Full list of author information is available at the end of the article
}

Consequently, most of the equipment in renewable and sustainable power generation is not fully utilized because of this limitation. The introduction of intelligent power consumption technologies can effectively compensate for the limitation of renewable and sustainable energy, so as to make full use of the energy and improve the utilization rate of the equipment. Furthermore, the improvement of the utilization rate of equipment is conductive to reducing the amount of equipment and energy consumption used for the production of such equipment. The popularity of intelligent power consumption technologies influences the utilization rate of equipment on both supply and demand sides. The existing problem of supply side is that power supply and consumption are not synchronized which results in large differences between peak load and valley load. Distribution networks have to expand the equipment capacity to cater for the peak load period which causes huge wastage and low utilization rate during the low demand period, whereas the largest problem of demand side is the uncertainty and control difficulty of load. The 
intelligent power consumption technologies and measures listed and analyzed in this paper aim to improve the utilization rate of distribution network equipment from supply side and demand side. The improvement of the utilization rate of equipment, under the premise of reliable power supply [3] and good power quality, can greatly reduce the required investment of distribution networks.

As the utilization rate of distribution network equipment is still low, the analysis of the influence of intelligent power consumption technologies on the utilization rate of distribution network equipment is essential. Several intelligent power consumption technologies and measures are reviewed and their specific influences on the utilization rate of distribution network equipment are summarized in this paper.

Since 1991, the Thai power utilities have adopted a demand side management (DSM) plan including a cool storage air conditioning program to improve the load factor of the power system [4]. The use of the cool storage air conditioning improves the utilization of base-load generating stations and avoids costly peaking stations, and a case study in the Thai power system estimated 25\% reduction in peak demand [5]. It is proposed that the large-scale promotion of EVs or PHEVs equipped with V2G systems will bring great effects on power systems in Denmark, Finland, Germany, Norway and Sweden [6]. As shown in [7], a time-of-use (TOU) tariff system implemented in Chile could promote a 5\% savings in power consumption during the peak period by comparing with the current systems, and provide distribution companies a total potential benefit of 811.7 million dollar for the 3-year study period (2005-2007). These researches prove that the intelligent power consumption technologies and measures listed in this paper are worth to be evaluated.

\section{Evaluation method and index of utilization efficiency of distribution network equipment}

The utilization rate of equipment needs to be quantified and assessed first in order to analyze the influence of intelligent power consumption technologies on the utilization rate of distribution network equipment. There are several evaluation indexes and in the section, the evaluation indexes and their application scope are reviewed.

\subsection{Burden rate of substations}

The maximum burden rate of equipment is usually used to evaluate the utilization level of individual equipment by the power supply enterprises [8]. The maximum burden rate of substations reflects the running condition of substations at their maximum burden in normal operating mode. It includes the calculation of light burden rate, heavy burden rate, overload rate and average burden rate of substations [9]. The average burden rate of substations is defined as the ratio of the total amount of electricity to the rated capacity of the substations, which can be used as the evaluation index [10]. This evaluation index is suitable for the evaluation of the utilization rate of substations under the voltage level above $110 \mathrm{kV}$ and is given as:

$$
\eta_{\text {average }}=\frac{E_{\text {all }}}{C_{T}}
$$

where $\eta_{\text {average }}$ is the average burden rate of substations, $E_{\text {all }}$ is the total amount of electricity, $C_{T}$ is the rated capacity of the substations.

Light burden substations are the substations whose burden rate is less than or equal to $30 \%$ in normal operation mode. The calculation of light burden rate of substations $\eta_{\text {light }}$ is given as:

$$
\eta_{\text {light }}=\frac{S_{\text {light }}}{S_{\text {all }}}
$$

where $\eta_{\text {light }} S_{\text {light }}$ is the number of light burden substations and $S_{\text {all }}$ is the number of all substations.

Heavy burden substations are the substations whose average burden rate is between the extreme burden rate and $100 \%$ in normal operation mode. Heavy burden rate $\eta_{\text {heavy }} \eta_{\text {heavy }}$ can be calculated as:

$$
\eta_{\text {heavy }}=\frac{S_{\text {heavy }}}{S_{\text {all }}}
$$

where

Overload substations are the substations whose burden rate is above $100 \%$ in normal operation mode, and the overload rate $\eta_{\text {over }}$ is given as:

$$
\eta_{\text {over }}=\frac{S_{\text {over }}}{S_{\text {all }}}
$$

where $\mathrm{S}_{\text {over }} \mathrm{S}_{\text {over }}$ is the number of overload substations.

The lower the values of light burden rate, heavy burden rate and overload rate, and the higher average burden rate, the better the utilization of substations is. In ideal cases, when the values of light burden rate, heavy burden rate and overload rate are 0 and the value of the average burden rate is up to $100 \%$, the substations are made the best use.

\subsection{Burden rate of lines}

The average burden rate of lines is defined as the ratio of the total amount of electricity to the rated capacity of the lines, which can directly reflect the utilization level of the line capacities in distribution networks. Therefore, it can be applied to evaluate the utilization rate of lines.

The maximum burden rate of lines reflects the running condition of lines at their maximum burden in normal operating mode. It includes the calculation of 
light burden rate, heavy burden rate, overload rate and average burden rate of lines, in a similar way to those of the substations [11].

\subsection{Capacity-load ratio}

Capacity-load ratio is the ratio of the total rated capacity of substation equipment in a certain power supply area to the average maximum active power of load being supplied [12]. As an important index to control the total capacity of substation equipment from a macro perspective, capacity-load ratio reflects the operating margin of substation equipment. The calculation of capacity-load ratio $\gamma_{c}$ is given as:

$$
\gamma_{c}=\frac{C_{T-\text { all }}}{P_{\max }}
$$

where $C_{T-\text { all }} \mathrm{C}_{\mathrm{T}-\text { all }}$ is the total rated capacity of substation equipment of a certain power supply area and $P_{\text {max }}$ is the average maximum active power of load being supplied.

However, the distribution of power load and substation capacity is usually uneven. Therefore, the general capacity-load ratio cannot accurately reflect the capacity margin of a single substation. The reasonable capacity-load ratio can be ascertained according to the expense of unit expansion, the rate of load increment and other special details. The reality of distribution networks should also be taken into consideration when selecting the capacity-load ratio of transformers. Optimal capacity-load ratio of multi-voltage distribution network is researched in [13] where the cost of construction and operation of distribution networks is set as the optimization objective and the service life of substation is considered as an optimization variable.

\subsection{Life cycle utilization rate}

The evaluation indexes of the utilization rate of distribution network equipment listed in the first three sections are presented only from one aspect. A comprehensive evaluation index named life cycle utilization rate [14] is proposed in this section. The purpose of life cycle assessment (LCA) is to find the optimal strategy to eliminate the effects by tracking influential factors and evaluating them in a systematic way [15]. The life cycle utilization rate of electrical equipment is an index that takes demand side, supply side and life cycle into consideration. This index takes the actual amount of electricity of equipment during its service life as a reference, which can give a comprehensive evaluation for the utilization rate of distribution equipment, rather than being limited to the service life of the equipment. The life cycle utilization rate can be denoted by the product of load rate, burden rate and life expectancy rate as:

$$
\begin{aligned}
\eta & =\frac{E_{a}}{C \times T_{d}}=\frac{L_{\text {ave }} \times T_{a}}{C \times T_{d}}=\frac{L_{\text {ave }}}{L_{\max }} \times \frac{L_{\max }}{C} \times \frac{T_{a}}{T_{d}} \\
& =\eta_{1} \times \eta_{2} \times \eta_{3}
\end{aligned}
$$

where $\eta$ is the life cycle utilization efficiency of electrical equipment, $E_{a} \mathrm{E}_{\mathrm{a}}$ is the actual amount of electricity during its service life, $C$ is the capacity of the electrical equipment, $T_{d}$ and $T_{a}$ are the design life and actual service life, respectively. $L_{\text {ave }} \mathrm{L}_{\text {ave }}$ and $L_{\text {max }}$ are the average loadL $L_{\max }$ and the maximum load, respectively. $\eta_{1} \eta_{1}$, $\eta_{2} \eta_{2}$ and $\eta_{3}$ are the load rate, burden rate, and life expectancy rate, respectively.

Load rate reflects the utilization rate of electrical equipment from the perspective of demand side, whereas burden rate reflects the utilization rate of electrical equipment from the perspective of supply side. For life expectancy rate, it reflects the utilization rate of electrical equipment during its whole life cycle.

The relationship of this evaluation index with the intelligent power consumption technologies and measures listed in this paper is shown in Fig. 1. Electrical energy storage technology stores energy during the valley period at night and releases it during the peak period in the day. Therefore, it can achieve peak load shifting and is beneficial to increase the load rate. It also eases the pressure of peak demand on the distribution network and decreases the burden of distribution network equipment, which can increase the life utilization rate of equipment. Through optimized charging of EVs, V2G technology can compensate for the low load demand at night and provide the stored energy of EVs for the distribution network during the peak period to ease the tight power supply. Therefore, the load rate is increased. The energy stored in the batteries of EVs can be served as the spare capacity of the power system and distribution network enterprises can decrease the capacity of equipment and the burden of the power system is unchanged. Therefore, the burden rate is increased. V2G technology can also reduce the loss of equipment which is beneficial

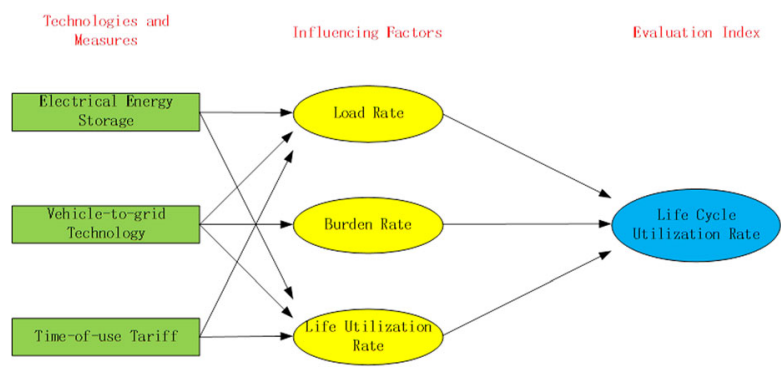

Fig. 1 The relationship of the evaluation indexes with the intelligent power consumption technologies and measures. The relationship of this evaluation index with the intelligent power consumption technologies and measures listed in this paper 
to improve their life utilization rate. In the meantime, TOU tariff can guide consumers to participate in peak load shifting through the price incentive to improve the load rate. Thus, distribution network enterprises don't need to cut the power when the power supply is tight by implementing TOU tariff. The frequency of switching distribution network equipment is also reduced, which is good for the improvement of the life utilization rate.

\section{Intelligent power equipment with energy storage function}

Energy storage plays a vital role in improving the utilization rate of intermittent energy and peak load shifting $[16,17]$. As one of the most economic and effective technologies in shifting peak load, electrical energy storage technology has a quite promising future. It can not only balance the load of distribution networks and improve the utilization rate of equipment, but also improve the utilization rate of energy and ease the energy crisis. Cool storage air conditioning, electrical boilers with heat storage and heat pump units are some of the widely used electrical energy storage technologies [18].

\subsection{Cool storage air conditioning}

The working principle of cool storage air conditioning technology is to use chiller to freeze water to ice or chilled water during the valley period at night, while in the peak period during the day, release the cold energy by melting the ice stored in the devices or in the chilled water to meet the demand of air conditioning. The common mediums used in cool storage air conditioning system are water and ice $[19,20]$. Chilled water storage uses sensible heat to store the cold energy while ice storage uses latent heat of phase change. The ice storage has large density, high efficiency and good ability of cool storage, can supply water and wind at low temperature and only requires small capacity of water pumps and fans, and has been widely used [21].

There are two typical cool storage modes known as full operating mode and partial operating mode [22].

\subsubsection{Full operating mode}

As shown in Fig. 2, the air conditioning system stores enough cold energy in non-air-conditioning period at night to meet the demand of all the air-conditioning load. Therefore, the air-conditioning load is shifted from the peak to the valley period. The chillers only store cold energy and the cool storage tank is used as a complete adjustable daily cold energy storehouse. The full operating mode is usually applied in places where the gap between the peak and the valley load is large, such as office buildings, complex buildings, shopping malls, hotels, hospitals, entertainment theaters and so on.

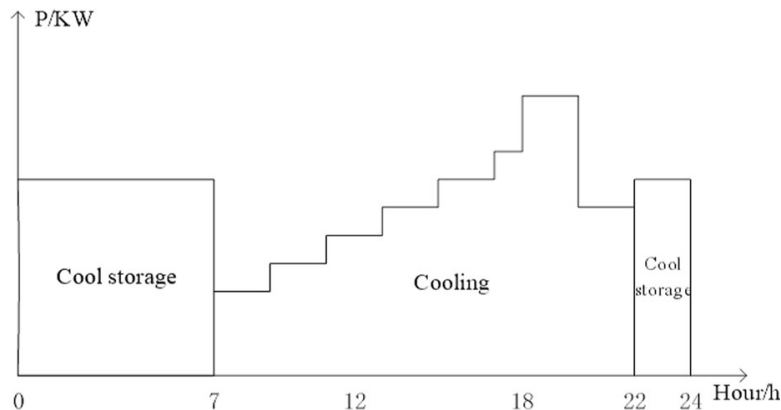

Fig. 2 Full operating mode. The air conditioning system stores enough cold energy in non-air-conditioning period at night to meet the demand of all the air-conditioning load. Therefore, the air-conditioning load is shifted from the peak to the valley period. The chillers only store cold energy and the cool storage tank is used as a complete adjustable daily cold energy storehouse

\subsubsection{Partial operating mode}

As shown in Fig. 3, the air conditioning system stores a certain amount of cold energy in non-air-conditioning period to meet part of the demand of air-conditioning load. During the peak period, the chillers are still working for cooling. Thus, part of air-conditioning load is shifted from the peak to the valley period. The daily demand of cold energy of the air conditioning system is provided by the chillers and the stored cold energy. The chillers not only store but also supply cold energy and the cool storage tank is used as an incomplete adjustable daily cold energy storehouse.

In [21], the energy utilization rate and the annual total operation cost including the investment cost, maintenance cost, operation cost and penalty charge for $\mathrm{CO} 2$ emissions are defined as the objective functions. Obtained from the multi-objective genetic algorithm, the

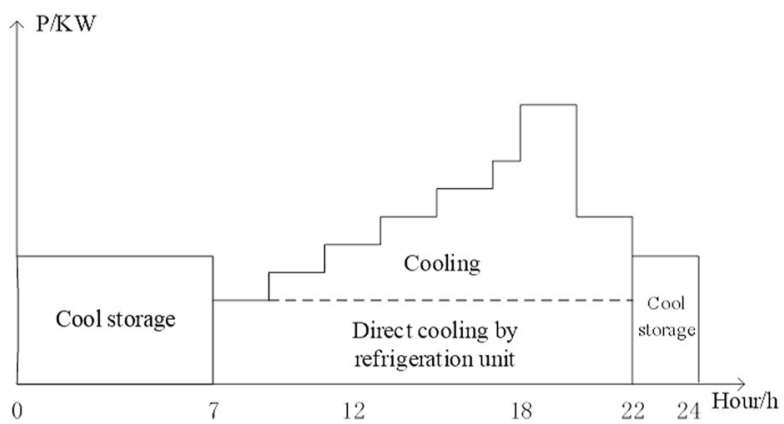

Fig. 3 Partial operating mode. The air conditioning system stores a certain amount of cold energy in non-airconditioning period to meet part of the demand of airconditioning load. During the peak period, the chillers are still working for cooling. Thus, part of air-conditioning load is shifted from the peak to the valley period. The daily demand of cold energy of the air conditioning system is provided by the chillers and the stored cold energy 
respective power consumptions of the ice storage system in the full and partial operating modes decrease by $11.83 \%$ and $10.23 \%$ under the condition of same cold energy storage and cooling load, when compared with the traditional system. A reduction in peak demand of $41 \%$ and $56 \%$ energy consumption shifting under TOU tariff are shown in a simulation of cool storage system for a typical university campus, and 38\% reduction in peak demand is possible for a typical office complex by using the chilled water storage strategy under TOU tariff [5]. The effects of chilled water storage air conditioning system and normal air conditioning system are compared in [23]. It concludes that, the chilled water units and water pump systems can reduce the daily peak demand of air conditioning systems by $36.7 \%-87.5 \%$ and reduce annual power consumption by $4.5 \%-6.9 \%$. In addition, compared with the traditional air conditioning system, the life cycle cost of the chilled water storage air conditioning system is reduced by $4 \%-8.9 \%$. The study proves that the electrical energy storage technology can effectively reduce the peak demand and the cost of power consumption. In [24], the development of a model for evaluating peak load reduction and change in overall energy consumption for a residential air conditioning compressor with and without condenser-side thermal storage is discussed. The thermal storage of air conditioning is provided by an integrated thermal energy and rainwater storage system (ITHERST). The model used simulated cooling load data for a typical home in Austin, Texas, based on the historical and typical meteorological year datasets in summer 2011. The analysis suggests that the ITHERST system with 3785-18,925 L of water could reduce peak compressor power demand by approximately $29 \%-53 \%$, compared to a traditional air conditioning with an air-cooled condenser. Although total compressor energy consumption increases 5\%-15\% because of the inefficiencies of re-cooling the thermal mass, this additional energy consumption occurs during low demand off-peak hours which has a good effect on the valley load filling.

\subsection{Electrical boilers with heat storage and heat pump} units

The working principle of electrical heat storage technology is to heat the medium using the electrical heat devices during the valley period and release the thermal energy at the peak period to meet the demand of buildings and houses [25-27]. The typical heat storage devices include electrical boilers with heat storage and heat pump units. The heat storage mediums include water, steam and other phase change materials [28]. Water heat storage can be divided into normal temperature and high temperature heat storage. The working principle of the electrical boilers is to heat the water to produce pressurized hot water or saturated steam and achieve the energy conversion by the high power electrical heating elements installed in the shell. Heat pump units are efficient energy-saving devices and the common heat pump systems include air source heat pump system, water source heat pump system, geothermal source heat pump system and solar/air dual source heat pump system. Their working principle is to pump the heat from heat sources in low grade to the energy storage devices continuously. There are two typical heat storage modes known as full operating mode and partial operating mode which are broadly similar to the cool storage systems.

In recent decades, electrical heat storage systems have demonstrated capabilities to reduce the peak load and change the way of power consumption, and consequently, they have the potential to become powerful instruments in DSM [29, 30]. In [31], a normal working day is divided into two parts of peak and off-peak hours, and the electricity price is cheaper during the off-peak period. It was found that with this strategy many users would shift their load to the off-peak hours and consequently, more peak capacities could be available for other uses, and off-peak capacity be better used.

\subsection{The influence on the utilization rate of distribution network equipment}

Applying electrical energy storage technology to industry and daily life through intelligent power consumption equipment can effectively improve the utilization rate of distribution network equipment.

Phase change materials perform functions of energy storage in intelligent power consumption equipment and are widely used in buildings for peak load shifting due to its good ability of thermal energy storage. The existing studies have demonstrated that they have a significant effect on peak load reduction with and without the implementation of load control strategies (from 10\% to 57\%) [32]. Different types of energy storage technologies have their own advantages and are suitable for different applications. Electrical energy storage technology, which can reduce the daily peak demand and the electrical equipment capacity of the enterprises, is beneficial to the full use of the existing equipment and the reduction of the investment cost [33]. Coordinating with the electricity price policy, it can also reduce the enterprises' operating cost.

Electricity shortage mostly occurs in the peak period of power consumption and the problem of the increasing gap between the load peak and load valley is not solved completely. With the process of production of new generator units, the gap of the total power supply of China will be gradually narrowed. But the problems of the expansion of the gap between the load peak and 
the load valley, the decrease of the utilization rate of generator units and the power shortage in the peak period still exist. DSM and demand response (DR) as the two most important methods in intelligent power consumption [34], are applied to encourage consumers to participate in shifting peak load, and have a great effect on the improvement of the utilization rate of distribution network equipment. Compared with the traditional DSM, DSM in smart grid, which has better load monitoring technology, intelligent control technology and terminal energy saving efficiency [35], can better achieve the balance between demand and supply to improve the utilization rate of equipment. Combining the DSM with the intelligent power equipment with energy storage function in a right way can shift the load from the peak to the valley period of distribution networks, improve the load rate and decrease the capacity of the distribution transformers. Therefore, strengthening the DSM and promoting the electrical energy storage technology have important significance.

\section{Vehicle-to-grid technology}

\subsection{The concept of V2G technology}

Electric vehicle charging and discharging technologies mainly have four modes, i.e. unidirectional disordered charging mode, unidirectional ordered charging mode, and bidirectional ordered charging and discharging modes. Unidirectional charging mode can only receive electricity from distribution networks, but cannot feed the surplus electricity of EVs back to distribution networks [36]. Bidirectional ordered charging and discharging modes mean that the EVs are connected with and controlled by the energy management system of distribution networks. The batteries of EVs are regarded as the moving power storage equipment and stand-by power source to realize the energy conversion with distribution networks [37].

The concept of V2G is proposed because power systems need to be compensated by other energy sources to stabilize the fluctuation caused by large scale integration of renewable resources into distribution networks. V2G technology has great potential to realize the interconnection between power systems and EVs due to its specific characteristic of enabling EVs to supply stored power to distribution networks [38].

To achieve V2G, two connections need to be established. One is the energy transmission connection which enables the electricity to transmit between distribution networks and EVs, and the other is the logic control connection which can accurately learn the operation state of distribution networks through the feedback signals [39].

\subsection{The influence on the utilization rate of distribution network equipment}

The integration of EVs into power systems affects distribution networks in many aspects such as transformers distribution lines, energy loss, power quality and the utilization rate and reliability of power systems [40]. As an important reference to the operation of power systems, the utilization rate of distribution network equipment is also affected by V2G technology and the integration of EVs into power systems.

The integration of EVs into distribution networks can effectively reduce the voltage fluctuation of the distribution network and improve the power quality and frequency control capability of the distributed generations (DG) [41]. V2G technology can greatly reduce the loss of distribution lines, avoid voltage drop and achieve smooth operation of the relay protection device. In addition, it also has great potential of peak load shifting and can ensure the safety of distribution networks and reduction of the operation cost [42-44]. EVs equipped with V2G systems play an important role in power systems. They can adjust active power, compensate reactive power, shift peak load, fill valley load and increase the load rate $[45,46]$. They can also provide spare capacity for distribution networks.

As an important part of smart grid technologies, V2G technology can achieve the interaction between distribution networks and EVs. The development of V2G technology will have a great influence on the future commercial operation mode of EVs. Research shows that plug-in hybrids electric vehicles (PHEVs) and pure EVs will become an indivisible part of the distribution systems within 20 years along with the development of smart vehicles and smart grid. They can provide energy storage, balance the demand of distribution networks and improve the ability of emergency power supply and the stability of distribution networks. Research also shows that more than $90 \%$ of passenger vehicles are driven about $1 \mathrm{~h}$ a day on average and $95 \%$ of the time is in idle state. If the number of EVs at standstill are large enough, they can be used as removable distributed energy storage devices when they are connected with distribution networks. Consequently, they can provide the surplus electricity to distribution networks while still meeting the driving demand of EV consumers.

In [47], American light vehicle fleet is quantitatively compared with power systems. The calculations suggest that V2G can stabilize large-scale (one-half of US electricity) wind power with $3 \%$ of the fleet dedicated to regulation for wind, plus $8 \%-38 \%$ of the fleet providing operating reserves or storage for wind. It is proposed in [48] that the capacity of the PHEV fleet equipped with V2G systems can be applied to balance the power system in the northeastern Brazilian. An incentivized 
auction-based group-selling approach for demand response management in V2G systems is proposed in [49]. Simulation results indicate that the proposed approach can help reduce the overall system cost of the grid compared to straightforward strategy of generating the same amount of extra electricity in peak period by generators. V2G technology combined with DSM can be used to provide the reserve by EVs for distribution networks in the peak period, thus effectively save the cost related to increasing generator units, reduce the loss of generators and improve the utilization rate of distribution network equipment. The function of V2G technology is to provide a large energy source and an energy outlet similar to a large buffer space for distribution networks. Many problems existing in distribution networks, including low energy utilization rate, large volatility of the power system and great differences of power demand in different periods, now have a new breakthrough.

The integration of distributed generation (DG) and the application of intelligent power consumption technologies affects the utilization rate of distribution network equipment [50-52].The application of V2G technology can effectively reduce the impact of distributed generations on distribution networks and improve the stability of the power system. V2G technology makes the participation in the power generation of large-scale wind, solar and other new energy sources possible. Wind and solar energy are unpredictable, fluctuant and intermittent due to the influence of weather, geography and period of time [53]. Therefore, directly integrating them into power systems can potentially make distribution networks unstable.

The largest output of solar energy is at noon while the wind energy is at night. They are both unpredictable which is similar to distribution networks. Ideally, power supply and consumption are synchronized as the storage space is limited. Otherwise the problem of electricity waste or tight power supply will occur.

According to the report from UK's "Guardian" in June 2009, the Danish government, the Danish Energy Association, Dong Energy of Demark and Siemens of Germany tested the use of EV batteries on wind energy storage on an island in Denmark. This project is called EDISON (Electric Vehicles in a Distributed and Integrated Market using Sustainable Energy and Open Networks), and in this project, the batteries of EVs being parked are used to store the excessive electricity when the wind is strong and then provide their stored electricity for distribution networks when there is no wind by utilizing V2G technology. Consequently, more wind turbines can be allowed to be constructed and up to $50 \%$ of the electricity can be provided by wind for the island without distribution network collapse. This project, with the involvement of 40,000 residents, is the largest demonstration application of V2G technology.
By utilizing V2G technology, the electricity generated by wind and solar energy can be stored in EV batteries and stably provided for distribution networks. Furthermore, if these EVs can communicate with each other and share their power in a smart way, the pressure of distribution networks in peak period can be significantly reduced.

The promotion of V2G technology can obviously optimize distribution networks. On the one hand, when EVs are charging, they can be seen as a load. The power suppliers can use technical and economic means to arrange the charging time and achieve ordered charging management which can achieve peak load shifting, improve the operation efficiency of the system and reduce the influence on distribution network safety. On the other hand, when the EV batteries are used as energy storage devices, they are seen as reserve capacity of distribution networks which can help provide electricity for the power system in peak period and optimize the operation of distribution networks. In addition, the power supply scheduling for EVs is carried out from the angle of the power grid, and its direct beneficiaries are power suppliers and operators with no consideration for the interests of EV users. However, EV users are the main body of V2G participation and they should formulate management strategies to find optimal solutions to maximize their interests. It is necessary to ensure the maximization of user benefits to attract more users to participate in V2G by charging and discharging control strategy. Similarly, during the operation of V2G, frequent charging and discharging will inevitably affect the life of batteries, and the resulting cost associated with battery loss should also be taken into consideration. Through the charge and discharge control strategy, the best operating conditions of the shallow charge and shallow discharge of the batteries are made as far as possible. This is of great significance to the promotion of the popularity of EV.

\section{Time-of-use tariff}

\subsection{The definition of TOU tariff}

Peak-valley TOU tariff means that $24 \mathrm{~h}$ of a day are divided into periods of peak, flat and valley and the electricity price of each period is drafted according to the load changes [54]. It is used to encourage consumers to arrange the time of power consumption rationally, which is good for peak load shifting and utilization rate of power resources.

As the most powerful economic leverage of the power enterprises, the role of electricity price policy in power system cannot be neglected. Rational use of electricity price policy can both meet the demand of consumers and make the power enterprises profitable. TOU tariff is an incentive method of price implemented by the power 
enterprises in DSM [55-57], and the policy is helpful to the stabilization of the load curve and the operation cost reduction of the power system.

\subsection{The influence on the utilization rate of distribution network equipment}

In [58], the operation mechanism of DR and the key technologies in smart grid are reviewed in detail, and the conclusion that DR can be applied to peak load shifting is also drawn in the paper. TOU tariff is a price-based DR. Residential load often has a significant seasonal and daily peak demand $[59,60]$. The implementation of peak-valley TOU tariff encourages consumers to shift their power load [61], and it is great for peak load shifting and improvement of the load rate during the peak and valley periods. The utilization rate of the capacity of the power system is improved and the energy is saved by implementing TOU tariff [62]. For the consumers, it is beneficial to reduce the cost of power consumption by using less electricity during peak period and more electricity during valley period. For the power enterprises, TOU tariff helps to reduce the investment cost and operation cost of distribution networks, and ensure the safe and stable operation of distribution networks. For the power generation enterprises, TOU tariff can be used to reduce the cost of shifting peak load. For the society, the implementation of TOU tariff is conducive to reducing or delaying the power investment and promoting the rational allocation of social resources. However, irrational peak-valley TOU tariff schemes may cause the consumers to respond excessively and reverse the load peak and valley, which indeed leads to a side effect on the reliability and economy of the power system.

In [63], a new and comprehensive procedure for the optimal pricing in TOU is presented in which the fuel cost is minimized and the optimal electricity price of different periods is determined. It is also concluded that intelligent implementation of TOU can decrease both the power generation and consumption cost and improve the reliability of distribution networks. In [64], a linear time energy management system scheduling algorithm is proposed and a group of ten residential energy hubs are involved in the study. The optimal strategies of the energy hubs in the TOU and the dynamic pricing mechanisms are compared, and the effect of the electrical storage system and renewable resources on the hubs' optimal strategies is studied. Simulations show that the energy hubs' daily cost will be reduced by using the proposed scheduling algorithm. The implementation of TOU tariff in iron and steel industry can minimize the total operational cost including fuel cost, equipment maintenance cost and the charge of exchange power with main grid as presented in [65]. TOU tariff serves as a cost-effective way to realize electricity demand response, which aims at relieving peak demand [66]. In [67], considering the factors such as the fluctuation of electricity demand, the load response of users to electricity price changes and user satisfaction, a pricing model of TOU tariff is established based on Power Grid Corp and single user game. Finally, by analyzing the power consumption characteristics of different users, the model is expanded to multiple user situations, and the optimal electricity price and optimal electricity consumption under different electricity price strategies are analyzed. Consumers' participation is critical to the success of TOU tariff programs. TOU tariff provides a new way for the power system regulation, and the change of initiative role from distribution networks to consumers can solve the problem of large peak-valley difference of power consumption more practically. The active response of demand side reduces the cost of capacity expansion of distribution networks in emergency situations and saves the operating cost. The existing equipment is made the best use at the same time and the utilization rate of equipment is greatly improved.

With the promotion of TOU tariff, consumers can arrange the time of power consumption according to the electricity price, thus avoiding or reducing power consumption during peak period and using the electricity during valley period. The load is shifted by using this method and the load rate of distribution networks is improved. The utilization rate of equipment capacity is also improved. All of above effects contribute to the utilization rate of distribution network equipment.

\section{Conclusion}

The utilization rate of distribution network equipment is closely related to the economy of distribution network construction. It depends on the load rate, burden rate and life expectancy rate of the equipment. Intelligent power consumption technologies play a significant role in improving the utilization rate of distribution network equipment which can reduce the construction and investment cost of distribution networks. The influence of intelligent power consumption technologies on the utilization rate of distribution network equipment is affected by a variety of factors. The key to improve the utilization rate of equipment is to take the problems of supply side and demand side into consideration comprehensively, and to make use of the intelligent power consumption technologies rationally. The corresponding evaluation indexes and their application scope are described in this paper, and the influences of intelligent power equipment with energy storage function, V2G technology and TOU tariff on the utilization rate of distribution network equipment have also been reviewed.

Intelligent power consumption equipment with energy storage function can store energy during the valley 
period of distribution networks and release energy to meet the demand during the peak period, which has a great effect on peak load shifting. It can also improve the load curve and the utilization rate of distribution network equipment. The wide adoption of EVs bring some issues to the operation of distribution networks, and the introduction of V2G technology aims to solve or mitigate such problems. V2G technology uses the capacity of EVs' batteries as the spare energy storage to provide electricity for distribution networks during the peak period which can reduce the cost related to generator units' expansion. In addition, EVs are orderly charged during the valley period which can have a good effect on valley load filling. The application of V2G technology reduces the loss of equipment to a certain degree and improves the load rate of distribution networks. However, there are many problems to be solved. As the direct beneficiaries of V2G are power suppliers and operators, whereas EV users are the main body of V2G participation, they should formulate management strategies to find optimal solutions to maximize their interests. Similarly, during the operation of V2G, frequent charging and discharging can inevitably affect the life of the batteries, and thus, the cost associated with the resulting battery loss should also be taken into account. There are many successful applications of TOU tariff which is used as an incentive method at home and abroad. On one hand, the implementation of TOU tariff decreases the gap between the load peak and load valley and relieves the pressure on distribution networks. On the other hand, the cost of consumers' power consumption is reduced. The implementation of rational schemes of TOU tariff is useful for peak load shifting and the improvement of utilization rate of the distribution network equipment. Because of the influence of the cost of the power demand fluctuation, a user's load response to the change of the electricity price and the user satisfaction, the TOU tariff model of the game between Power Grid Corp and the single user needs to be further optimized. It is necessary to make a more in-depth study on the power consumption characteristics of different users and establish a better TOU tariff model.

All of these technologies and measures have an influence on the load rate and can improve the load curve which is beneficial to peak load shifting. The influence of the load rate on the utilization rate of distribution network equipment is full discussed. However, the researches on the burden rate and life expectancy rate are not sufficient and require further discussion.

\section{Abbreviations}

DG: Distributed generation; DR: Demand response; DSM: Demand side management; EV: Electric vehicle; ITHERST: Integrated thermal energy and rainwater storage system; LCA: Life cycle assessment; PHEVs: Plug-in hybrids electric vehicles; TOU: Time-of-use; V2G: Vehicle-to-grid

\section{Acknowledgements}

This work is supported by State Grid Corporation of China (5216A018000M). The authors also sincerely thank the organizations and individuals, whose work has been cited in this article.

Availability of data and materials

Data sharing not applicable to this article as no datasets were generated or analysed during the current study.

\section{Authors' contributions}

$\mathrm{YQH}$ analyzed the influence of intelligent power technology on the utilization ratio of distribution network equipment and drafted the manuscript. YHC analyzed the influence of the intelligent electrical equipment containing the implicit energy on the utilization ratio of the distribution network equipment. ZQY analyzed the effect of vehicle-to-grid technology and time-of-use on the utilization ratio of distribution network equipment. HBH conceived of the study and helped to draft the manuscript. LL participated in the design of the study and performed the statistical analysis. All authors read and approved the final manuscript.

\section{Competing interests}

The authors declare that they have no competing interests.

\section{Author details}

'Beijing Hengtong of Polytron Technologies Inc, Nongda Road No. 1 Silicon Valley City No. 2 building block A Room 401, Beijing City, Haidian District, China. ${ }^{2}$ College of Electric and Information Engineering, Hunan University, Yuelu District, Changsha, Hunan Province, China.

Received: 23 March 2018 Accepted: 31 May 2018

Published online: 19 June 2018

\section{References}

1. Zhang, Y., Zhang, X., Li, Q., et al. (2014). Gray theory based energy saving potential evaluation and planning for distribution networks []]. International Journal of Electrical Power \& Energy Systems, 57, 298-303.

2. Feng, L., Zhang, J., Li, G., et al. (2016). Cost reduction of a hybrid energystorage system considering correlation between wind and PV power [J]. Protection Control Modern Power Systems, 1(1), 11.

3. Koziolek, A., Avritzer, A., Suresh, S., et al. (2016). Assessing survivability to support power grid investment decisions [J]. Reliability Engineering and System Safety, 155, 30-43.

4. Limmeechokchai, B., \& Chungpaibulpatana, S. (2001). Application of cool storage air-conditioning in the commercial sector: An integrated resource planning approach for power capacity expansion planning and emission reduction [J]. Applied Energy, 68(3), 289-300.

5. Ashok, S., \& Banerjee, R. (2003). Optimal cool storage capacity for load management [J]. Energy, 28(2), 115-126.

6. Fathabadi, H. (2015). Utilization of electric vehicles and renewable energy sources used as distributed generators for improving characteristics of electric power distribution systems [J]. Energy, 90, 1100-1110.

7. Vera, S., Bernal, F., \& Sauma, E. (2013). Do distribution companies loose money with an electricity flexible tariff?: A review of the Chilean case [J]. Energy, 55, 295-303.

8. An, X. H., Ouyang, S., Feng, T. R., et al. (2016). Optimized design method and application of benchmark of theoretical loss rate of medium-voltage lines (in Chinese) [J]. Power System Technology, 40(1), 199-206.

9. Yang, W. H., Liu, H., Wang, Z., et al. (2012). Study on evaluation index system of equipment utilization on distribution network[C]// Innovative Smart Grid Technologies - Asia. IEEE, 1:1-5.

10. Luo, F., Wang, C., Xiao, J., et al. (2010). Rapid evaluation method for power supply capability of urban distribution system based on N-1 contingency analysis of main-transformers [J]. International Journal of Electrical Power \& Energy Systems, 32(10), 1063-1068.

11. ElA. Electric power annual 2015. Energy Information Administration; 2015. Available at: <http://www.eia.gov/electricity/annual/pdf/epa.pdf>.

12. Li, X. R., Liu, Y. Q., Zhu, X. Y., et al. (2006). Study on capacity-load ratio of medium-voltage distribution network (in Chinese) [J]. Power System Protection and Control, 34(7), 47-50. 
13. Li, Z. K., Liu, D. W., Wei, C. F., et al. (2012). Optimal capacity-load-ratio research of the multi-voltage distribution network [J]. Advances in Materials Research, 614-615, 733-742.

14. Hu, Z. L., Zhang, Y. J., Li, C. B., et al. (2015). Utilization efficiency of electrical equipment within life cycle assessment: Indexes, analysis and a case [J]. Energy, 88, 885-896.

15. Hellweg, S., Milà, i., \& Canals, L. (2014). Emerging approaches, challenges and opportunities in life cycle assessment [J]. Science, 344(6188), 1109-1113.

16. Kalkhambkar, V., Kumar, R., \& Bhakar, R. (2016). Energy loss minimization through peak shaving using energy storage [J]. Perspectives in Science, 8 , $162-165$.

17. Lucas, A., \& Chondrogiannis, S. (2016). Smart grid energy storage controller for frequency regulation and peak shaving, using a vanadium redox flow battery [J]. International Journal of Electrical Power \& Energy Systems, 80, 26-36.

18. Yu H, Duan J, Du W, et al. (2017). China's energy storage industry: Develop status, existing problems and countermeasures [J]. Renewable and Sustainable Energy Reviews, 71:767-784.

19. Wang, X., Dennis, M., \& Hou, L. (2014). Clathrate hydrate technology for cold storage in air conditioning systems [J]. Renewable and Sustainable Energy Reviews, 36, 34-51.

20. Arcuri, B., Spataru, C., \& Barrett, M. (2017). Evaluation of ice thermal energy storage (ITES) for commercial buildings in cities in Brazil [J]. Sustainable Cities \& Society, 29, 178-192.

21. Sanaye, S., \& Hekmatian, M. (2016). Ice thermal energy storage (ITES) for airconditioning application in full and partial load operating modes [J]. International Journal of Refrigeration, 66, 181-197.

22. Zhai, X. Q., Wang, X. L., Wang, T., et al. (2013). A review on phase change cold storage in air-conditioning system: Materials and applications [J]. Renewable and Sustainable Energy Reviews, 22(8), 108-120.

23. Sebzali, M. J., Ameer, B., \& Hussain, H. J. (2014). Comparison of energy performance and economics of chilled water thermal storage and conventional air-conditioning systems [J]. Energy and Buildings, 69, 237-250.

24. Upshaw, C. R., Rhodes, J. D., \& Webber, M. E. (2015). Modeling peak load reduction and energy consumption enabled by an integrated thermal energy and water storage system for residential air conditioning systems in Austin, Texas [J]. Energy and Buildings, 97, 21-32.

25. Boait P J, Snape J R, Darby S J, et al. (2016). Making Legacy Thermal storage heating fit for the smart grid [J]. Energy \&Buildings, 138:630-640.

26. Zhang, N., Lu, X., Mcelroy, M. B., et al. (2016). Reducing curtailment of wind electricity in China by employing electric boilers for heat and pumped hydro for energy storage [J]. Applied Energy, 184, 987-994.

27. Wong, S., \& Pinard, J. P. (2017). Opportunities for smart electric thermal storage on electric grids with renewable energy [J]. IEEE Transactions on Smart Grid, 8(2), 1014-1022.

28. Huang, X., Alva, G., Jia, Y., et al. (2017). Morphological characterizationand applications of phase change materials in thermal energy storage: A review [J]. Renewable and Sustainable Energy Reviews, 72, 128-145.

29. Al-Abidi, A. A., Mat, S. B., Sopian, K., et al. (2012). Review of thermal energy storage for air conditioning systems [J]. Renewable and Sustainable Energy Reviews, 16(8), 5802-5819.

30. Arteconi, A., Hewitt, N. J., \& Polonara, F. (2012). State of the art of thermal storage for demand-side management [J]. Applied Energy, 93(5), 371-389.

31. Rismanchi, B., Saidur, R., Boroumandjazi, G., et al. (2012). Energy, exergy and environmental analysis of cold thermal energy storage (CTES) systems [J]. Renewable and Sustainable Energy Reviews, 16(8), 5741-5746.

32. Sun, Y., Wang, S., Xiao, F., et al. (2013). Peak load shifting control using different cold thermal energy storage facilities in commercial buildings: A review [J]. Energy Conversion and Management, 71(3), 101-114.

33. Kumar V, Hewage $K$, Haider $H$, et al. (2017). Sustainability evaluation framework for building cooling systems: a comparative study of snow storage and conventional chiller systems [J]. Clean Technologies and Environmental Policy, 19(1):137-155

34. Morales, D. X., Besanger, Y., Sami, S., et al. (2017). Assessment of the impact of intelligent DSM methods in the Galapagos Islands toward a smart grid [J]. Electric Power Systems Research, 146, 308-320.

35. Dong, J., Xue, G., \& Li, R. (2016). Demand response in China: Regulations, pilot projects and recommendations - a review [J]. Renewable and Sustainable Energy Reviews, 59, 13-27.

36. Bae, S., \& Kwasinski, A. (2012). Spatial and temporal model of electric vehicle charging demand [J]. IEEE Transactions on Smart Grid, 3(1), 394-403.
37. Ma, Y., Houghton, T., Cruden, A., et al. (2012). Modeling the benefits of vehicle-to-grid technology to a power system [J]. IEEE Transactions on Power Apparatus and Systems, 27(2), 1012-1020.

38. Su, W. C., Eichi, H., Zeng, W. T., et al. (2012). A survey on the electrification of transportation in a smart grid environment [J]. IEEE Transactions on Industrial Informatics, 8(1), 1-10.

39. Habib, S., Kamran, M., \& Rashid, U. (2015). Impact analysis of vehicle-to-grid technology and charging strategies of electric vehicles on distribution networks - a review [J]. Journal of Power Sources, 277, 205-214.

40. Darabi, Z., \& Ferdowsi, M. (2011). Aggregated impact of plug-in hybrid electric vehicles on electricity demand profile [J]. IEEE Transactions on Sustainable Energy, 2(4), 501-508.

41. Shareef, H., Islam, M., \& Mohamed, A. (2016). A review of the stage-of-the-art charging technologies, placement methodologies, and impacts of electric vehicles [J]. Renewable and Sustainable Energy Reviews, 64, 403-420.

42. Ehsani, M., Milad Falahi, M., \& Lotfifard, S. (2012). Vehicle to grid services: Potential and applications [J]. Energies, 5(10), 4076-4090.

43. Drude, L., Pereira Junior, L. C., \& Rüther, R. (2014). Photovoltaics (PV) and electric vehicle-to-grid(V2G)strategies for peak demand reduction in urban regions in Brazil in a smart grid environment [J]. Renewable Energy, 68, 443-451.

44. Ma, Z., Callaway, D. S., \& Hiskens, I. A. (2013). Decentralized charging control of large populations of plug-in electric vehicles [J]. IEEE Transactions on Control Systems Technology, 21(1), 67-78.

45. Michael CW Kintner-Meyer, Kevin P. Schneider, Robert G. Pratt. (2007). Impacts assessment of plug-in hybrid vehicles on electric utilities and regional US power grids: Part 1: Technical analysis [J]. Online Journal of Euec Paper, 1:01-19.

46. Sortomme, E., \& El-Sharkawi, M. A. (2012). Optimal scheduling of vehicle-to-grid energy and ancillary services [J]. IEEE Transactions on Smart Grid, 3(1), 351-359.

47. Kempton, W., \& Tomić, J. (2005). Vehicle-to-grid power implementation: From stabilizing the grid to supporting large-scale renewable energy [J]. Journal of Power Sources, 144(1), 280-294.

48. Borba, B. S. M. C., Szklo, A., \& Schaeffer, R. (2012). Plug-in hybrid electric vehicles as a way to maximize the integration of variable renewable energy in power systems: The case of wind generation in northeastern Brazil [J]. Energy, 37(1), 469-481.

49. Zeng, M., Leng, S., Maharian, S., et al. (2015). An incentivized auction-based group-selling approach for demand response management in V2G systems [J]. IEEE Transactions on Industrial Informatics, 11(6), 1554-1563.

50. Singh, B., \& Sharma, J. (2017). A review on distributed generation planning [J]. Renewable and Sustainable Energy Reviews, 76, 529-544.

51. Vyas, S., Kumar, R., \& Kavasseri, R. (2017). Data analytics and computational methods for anti-islanding of renewable energy based distributed generators in power grids [J]. Renewable and Sustainable Energy Reviews, 69, 493-502.

52. Singh B, Pal C, Mukherjee $V$, et al. (2016). Distributed generation planning from power system performances viewpoints: A taxonomical survey [J]. Renewable and Sustainable Energy Reviews, 75:1472-1492.

53. Li, H., Eseye, A. T., Zhang, J., et al. (2017). Optimal energy management for industrial microgrids with high-penetration renewables [J]. Protection \& Control of Modern Power Systems, 2(1), 12.

54. Yang, L., Dong, C. W., Johnny Wan, C. L., et al. (2013). Electricity time-of-use tariff with consumer behavior consideration [J]. International Journal of Production Economics, 146(2), 402-410.

55. Mohajeryami, S., Moghaddam, I. N., Doostan, M., et al. (2016). A novel economic model for price-based demand response [J]. Electric Power Systems Research, 135, 1-9.

56. Srinivasan, D., Rajgarhia, S., Radhakrishnan, B. M., et al. (2017). Game-theory based dynamic pricing strategies for demand side management in smart grids [J]. Energy, 126, 132-143.

57. Khan, A. R., Mahmood, A., Safdar, A., et al. (2016). Load forecasting, dynamic pricing and DSM in smart grid: A review [J]. Renewable and Sustainable Energy Reviews, 54, 1311-1322.

58. Wang, F., Xu, H., Xu, T., et al. (2017). The values of market-based demand response on improving power system reliability under extreme circumstances [J]. Applied Energy, 193, 220-231.

59. Haider, H. T., See, O. H., \& Elmenreich, W. (2016). A review of residential demand response of smart grid [J]. Renewable and Sustainable Energy Reviews, 59, 166-178.

60. Friess, W. A., \& Rakhshan, K. (2017). A review of passive envelope measures for improved building energy efficiency in the UAE [J]. Renewable and Sustainable Energy Reviews, 72, 485-496. 
61. Matar, W. (2017). A look at the response of households to time-of-use electricity pricing in Saudi Arabia and its impact on the wider economy [J]. Energy Strategy Reviews, 16, 13-23.

62. Kilkki, O., Alahaivala, A., \& Seilonen, I. (2015). Optimized control of pricebased demand response with electric storage space heating []]. IEEE Transactions on Industrial Informatics, 11(1), 281-288.

63. Dehnavi, E., \& Abdi, H. (2016). Optimal pricing in time of use demand response by integrating with dynamic economic dispatch problem [J]. Energy, 109, 1086-1094.

64. Kamyab, F., \& Bahrami, S. (2016). Efficient operation of energy hubs in timeof-use and dynamic pricing electricity markets [J]. Energy, 106(1), 343-355.

65. Zeng, Y. J., \& Sun, Y. G. (2015). Short-term scheduling of steam power system in Iron and steel industry under time-of-use power price [J]. Journal of Iron and Steel Research International, 22(9), 795-803.

66. Wang, Y. \& Li, L. (2015). Time-of-use electricity pricing for industrial customers: A survey of U.S. utilities [J]. Applied Energy, 149, 89-103.

67. Dong, J., Zhang, X. H., Li, C. X., et al. (2016). Optimal TOU pricing strategy considering user satisfaction in automated demand response background []]. Electric Power Automation Equipment, 36(7), 67-73.

\section{Submit your manuscript to a SpringerOpen ${ }^{\circ}$ journal and benefit from:}

- Convenient online submission

- Rigorous peer review

- Open access: articles freely available online

- High visibility within the field

- Retaining the copyright to your article

Submit your next manuscript at $\gg$ springeropen.com 